\title{
The Analytical Expression of Steady-State Concentration of Mixture of Toluene and N- Propanol in the Biofilm: Akbari- Ganji's Method
}

\author{
R. Vanaja ${ }^{1}$, P. Jeyabarathi ${ }^{2}$, L. Rajendran ${ }^{1, *}$, M.E.G. Lyons ${ }^{3}$ \\ ${ }^{1}$ Department of Mathematics, AMET (Deemed to be university) chennai, Tamilnadu, India. \\ ${ }^{2}$ Department of Mathematics, Government Arts College, Ariyalur, Affiliated to Bharathidasan \\ University, Thiruchirappalli, India \\ ${ }^{3}$ School of Chemistry and AMBER National Centre, University of Dublin, Trinity College Dublin, \\ Dublin 2, Ireland \\ *E-mail: raj_sms@ rediffmail.com
}

Received: 18 December 2021 / Accepted: 16 January 2022 / Published: 2 February 2022

This paper discusses the biofiltration of toluene and propanol mixtures in a biofilter filled with a compost-woodchip combination. The base of the model is the mass transfer at the biofilm interface and chemical oxidation in the biofilm and gas phases. For all feasible experimental values of parameters, an approximate analytical expression of propanol and toluene concentration profiles in both phases has been determined using Akbari-Ganji's method. In addition, the numerical solution of the problem is provided in this paper using Matlab software. The obtained results are validated with the available numerical and previous results. The model presented here can be utilized to design purposes.

Keywords Mathematical modelling; nonlinear equation; numerical simulations; toluene, $n$ - propanol; Akbari-Ganji's method (AGM)

\section{FULL TEXT}

(C) 2022 The Authors. Published by ESG (www.electrochemsci.org). This article is an open access article distributed under the terms and conditions of the Creative Commons Attribution license (http://creativecommons.org/licenses/by/4.0/). 